\title{
Moralejas en la oscuridad: la fábula en El Salvador del siglo XIX
}

Carlos Cañas-Dinarte

Aunque hoy es indudable poder afirmar que la literatura nacional surge con los poemas y escritos políticos del bicentenario poeta $\mathrm{Mi}$ guel Álvarez Castro (¿1795-1855?), no fue sino hasta mediados de la segunda década del siglo XIX cuando se manifestaron los primeros intentos locales por escribir fábulas ${ }^{1}$, emanados entre las disputas y batallas por la consolidación de los nacientes Estados, el establecimiento de la federación centroamericana y el brote de los intereses caudillistas de la época.

Así fue como surgieron los anónimos pininos de fabulación en las páginas de El semanario politico mercantil de San Salvador ${ }^{2}$ y El salvadoreño ${ }^{3}$. En el primero se localiza $E l$ sacristán y el labrador, texto en que su redactor critica a los ciudadanos salvadoreños que esperan rápidos resultados del nuevo régimen político recién independizado de España (1821) y México (1823). Por su parte, en el otro semanario puede leerse El lobo y la oveja, fábula relativa al desastre de los afanes federalistas, sostenidos por algunos pensadores y políticos de las Provincias Unidas del Centro de América: 


\section{El sacristán y el labrador}

Un sacristán que pasaba por una frondosa vega, a un labrador que sudando limpiaba su sementera, de esta manera le dijo en tono de burla y befa: "Dos meses ba que le veo afanado en esta siembra desde la aurora a la noche con tesón y diligencia: ¿No me dirá, buen amigo, qué el fruto de sus penas? Al cabo de sus afanes, ¿qué adelanta o aprovecha? ¿No empleara mejor el tiempo que gasta en tantas frioleras,

en enseñar la doctrina a los niños de la aldea...?”.

El labrador le responde, agitado en la tarea, por no decirle otra cosa... "Amigo, U. me dispensa, entiende $U$. tanto de eso como yo de hacer calcetas.

Piensa U. que esto es lo mismo que estar sentado en la iglesia, ¿que repicar las campanas $y$ venga acá la peseta...? Primeramente es preciso arar y solear la tierra, echarle el grano, y regarla para que la planta crezca y estando ésta ya crecida limpiarla de malas hierbas: pero esto es obra del tiempo, del cuidado y la paciencia;

$y$ si quisiera en dos dias sembrar y alzar cosecha, repito, ¿piensa U. que esto es soplar y hacer limetas?

Cierto, señor ignorante, ique es capricho y gran tontera!

Fuese el sacristán corrido al escuchar la respuesta, $y$, como suele decirse, con el rabo entre las piernas.

\section{El árbol recién nacido} en nuestro libre sistema no puede darnos tan pronto los frutos que se desean, pues que son obra del tiempo, del cuidado y diligencia. Son muchos los sacristanes que en el momento quisieran de la libertad naciente estrechar las conveniencias; pero a cada uno daría del labrador la respuesta: Amigo, ¿piensa U. que esto es soplar y hacer limetas?

Cierto, señor ignorante, ique es capricho y gran tontera! 
Si queréis ver pintada diestramente

De viles adversarios la falacia,

Si conocer deseáis la aristocracia,

Atención a la fábula siguiente.

\section{El lobo y la oveja}

Cruzando montes y trepando cerros

Aqui mato, alli robo, Andaba cierto lobo,

Hasta que dio en las manos de los perros.

Mordido y arrastrado,

Fue de sus enemigos velozmente, Quedó con vida milagrosamente, Mas inválido al fin y derrotado. Iba el tiempo curando su dolencia;

El hambre al mismo paso le afligía;

Pero como cazar aún no podía, Con las hierbas hacia penitencia.

Una oveja pasaba, y él le dice: "Amiga, ven acá, llega el momento,
Enfermo estoy y muerto de sediento,

Socorre con el agua a este infelice." "iAgua queréis que yo vaya a llevarte!", Le respondió la oveja recelosa.

"Dime, pues, una cosa:

Sin duda que será para enjuagarte,

Limpiar bien el güergüero, Abrir el apetito

$Y$ tragarme después como a un pollito.

Anda que te conozco, marrullero." Asi dijo y se fue, si no la mata.

iCuánto importa saber con quienes se trata!

Un par de meses más adelante y firmada sólo por un nebuloso apellido Mora aparecerá en $E l$ salvadoreño la composición fabulesco-satírica $E l$ sordo y el ciego, a cuya publicación seguirán las de los trabajos La criada maligna y Cáustico, texto este último reproducido del periódico mexicano $E l$ sol y en el que se abordan con acritud las ridiculeces de un eclesiástico engreído.

Años más tarde, cuando casi han cesado los combates librados por las tropas de Arce, Morazán y otros caudillos liberales y conservadores de la época, la pluma del malogrado soldado morazanista, poeta y dramaturgo Francisco Díaz (1812-1845) dará una personal voz de alerta sobre la fragmentación ístmica, publicada a doble columna en el periódico $E l$ amigo del pueblot:

Moralejas en la oscuridad: la fábula en El Salvador del siglo XIX 


\section{[Sobre la Unión Centroamericana]}

En una casa de campo que al caminante ofrecía por sus prados pintorescos la más bella perspectiva. El dueño bonrado y prudente pasaba su dulce vida en inocentes placeres $y$ en ocupación continua. Laborando diestramente las muy fértiles campiñas, $y$ aumentando sus ganados que por do quiera pacian.

En el rústico edificio

mil distracciones habia que indicaban el buen gusto del poseedor de la quinta. Aqui una risueña fuente de agradable y tersa linfa, apacible y deliciosa, convidaba a sus orillas: Alli un jardín muy vistoso que mil aromas vertia, embalsamaba las auras y destilaba ambrosia: Allá las jaulas doradas, en el techo suspendidas, depósito de las aves que melifluamente trinan. Todo ostentaba aquel gusto delicado, y la armonia, $y$ el orden, $y$ todo, todo recreaba y entretenía.

Pero lo más divertido y útil que alli se advertía era el hermoso rebaño que por el prado pacía.
En él todo su cuidado el propietario ponía, y su progreso era siempre el objeto de sus miras.

Las inocentes ovejas al dueño correspondian, produciendo sus hijuelos que el verlos era delicia. Así quieto lo pasaba el Selvático en su quinta, muy tranquilo en su conciencia, pero objeto de la envidia. Pues desde que del padrastro se separaron en vida $y$ se partieron las tierras todos los de la familia: Unos hermanos vecinos, esclavos de su codicia, a esta habitación hermosa todo su encono dedican. Con aire preponderante arrebatarla querian al bermano, $y$ absorberse las otras cercanas fincas.

Para esto inventan tramoyas, $y$ con astucias e intrigas, ya corrompen los pastores, y ya preparan conquistas. Mas viendo que al propietario, defendiendo su justicia, los bacendados vecinos sus esfuerzos le ofrecian: Recurren a los extraños (a tal llegó su perfidia) para someter por fuerza los de su misma familia. 
Pero aquel por dicha tiene una casta la más fina de perros fieles y bravos, de amistad alegoría.

Con estos y los pastores aguarda las tentativas de los injustos hermanos que a sus tierras se aproximan.

Viendo estos la decisión dudan, tiemblan, se retiran $y$ se quejan del bonrado que sus bienes defendia. Indignamente le insultan, le deshonran y concitan el odio de otro vecino que se vende a sus intrigas. En tanto una raza extraña, que estos disturbios atiza, sordamente se usurpaba algunas tierras baldias.
Llegaba a tal su descaro que volvió en si la familia, se reunió y tomó sus medios

para impedir la rapiña.

El modo más adecuado de vivir en paz meditan $y$ fue lanzar al soberbio que ocasionaba las riñas. Así siempre las contiendas buyen, y los que maquinan, extranjeros en el país, deben pagar su osadía. iOb quién extirpar pudiera el mal que nos contamina reprimiendo a los malvados que las discordias atizan! Queriendo ser superiores a toda la gran familia $y$ enseñorearse del Centro $y$ gobernar a la antigua.

En 1847, la semanal Gaceta del gobierno supremo del Estado del Salvador ${ }^{5}$ publicó una extensa composición fabulesca, poseedora de una clara tendencia política contra el imperialismo inglés del momento, representado en Centro América por el cónsul Frederick Chatfield. Calzado con las iniciales S. C. (quizá del joven poeta romántico Samuel Cuéllar, 1830-1857) y fechada en la ciudad de Guatemala a comienzos de abril de 1845, dicho trabajo estaba titulado como La fábula de las abejas y las arañas.

En el período comprendido entre marzo de 1850 y enero de 1852, los talleres sansalvadoreños del periódico oficial Gaceta del Salvador en la república de Centro América incluyeron en algunos de sus tirajes varias fábulas, amparadas en seudónimos o sin firmas al calce.

Casi ocultas en medio de decretos, acuerdos, avisos y anuncios, en la cuarta página de cada emisión semanal del órgano gubernamental fueron impresos esos breves textos de tinte cívico y político, dirigidos al pueblo centroamericano como ente social que estaba llamado a ser baluarte de la naciente democracia. 
Es probable que varios de esos trabajos fabulescos fueran reproducciones de algunas de las veintinueve fábulas políticas, "dedicadas al pueblo libre", que publicó J. M. Gutiérrez de Alva en el Calendario de 1851, impreso por la tipografía guatemalteca de Luciano Luna y comercializado en San Salvador en la casa del músico J. Escolástico Andrino, situada en el $\mathrm{N}^{\circ} 1$ de la antigua Calle del Comercio - actual 6a. avenida norte- 6 .

Entre esos textos poéticos figuraban los titulados Fábula, El peral, El niño y el busto, El incendio, La coalición de los animales, Las abejas, Las mujeres con mando, Los lobos viejos y los jóvenes, El gallo y el cigarrón, y El carro y el perro.

En el mismo semanario, entre 1852 y 1853 el negocio La librería publicó anuncios ${ }^{7}$ en los que comunicaba que, en su local san salvadoreño de la misma Calle del Comercio, $\mathrm{N}^{\circ} 20$, tenía a disposición de los intelectuales y público interesado una serie de libros recién importados de las casas editoras europeas.

Acompañados de gramáticas, manuales de mitología, novelas de amor, libros científicos, jurídicos y religiosos, figuraban en el catálogo de esa librería decimonónica volúmenes individuales de las fábulas de Esopo —en griego y traducción castellana—, Fedro —en latín y castellano-, Iriarte y Samaniego.

Un año después, el vate y ministro estatal Enrique Hoyos (1810$1859)^{8}$ inició la teorización de la fabulística nacional cuando escribió: "El apólogo es una de las formas de nuestra composición literaria. Natural y sencillo como la infancia, ni exige adorno, ni usa artificio. Los antiguos le tenían en gran estima, y la feliz introducción de los irracionales y aun de las cosas inanimadas en los consejos de moral, para que nos sirvan de ejemplo y de doctrina, ha hecho célebres los nombres de Fedro y Esopo. Bocaccio, La Fontaine, Iriarte y Samaniego pueden pasar por los Fedros de los tiempos modernos y nuestro contemporáneo y compatriota [García] Goyena, por el Esopo de la América Central".

A los anteriores conceptos, Hoyos añadió: "El apólogo puede emplearse en lo más elevado y en lo más humilde y, a la manera de magnetismo, obra con igual potencia sobre un diamante que sobre la cabeza de un alfiler. Puede aplicarse a lo grande y a lo pequeño; puede abrazar cuanto hay de espiritual, de místico y de teúrgico en las creencias; y cuanto hay de material y de variable en las costumbres de los 
hombres; al mundo visible y al mundo invisible; los ímpetus del cuerpo y el frenesí del alma; lo más depravado y lo más sublime; las virtudes más elevadas, así como las pasiones más bajas y los antojos más extraños de nuestra especie" .

Dos años más tarde, el periódico vicentino El rol acogía una Fábula política, de clara intención liberal, firmada por un desconocido L. L. en Santa Ana, el 26 de enero de $1856^{10}$.

Pocos días después y en el marco de la llamada "guerra nacional" contra los mercenarios filibusteros de William Walker que invadieron a la vecina tierra de los lagos (1856-1857), el patriotismo reinante en Centro América permitió que el órgano oficial salvadoreño diera cabida a un trabajo anónimo, adaptado de Samaniego, que ostentaba el título de La democracia nicaragüense y los filibusteros ${ }^{11}$.

En octubre de 1857, la marca de los fabulistas clásicos se hizo sentir de nuevo entre las personas lectoras e intelectuales cuando la Imprenta Nacional -establecida en Cojutepeque con motivo del megasismo que destruyó a San Salvador el 16 de abril de 1854- publicó anuncios de periódico ${ }^{12}$ para promover la venta de varios libros empastados en rústica. Entre ellos se encontraban una nueva edición de los trabajo de Iriarte - con seis fábulas agregadas-y dos volúmenes de las fábulas de Fedro, en latín y castellano, profusamente anotados.

Con espíritu polémico y antes del derrocamiento del régimen presidencial del general Gerardo Barrios y como epígono de aquel tipo inicial de fábula política, la Gaceta oficial ${ }^{13}$ imprimió la fábula conservadora Las abejas y los zánganos (1863), calzada por J. L. Mera, personaje cuya nacionalidad salvadoreña abriga serias dudas.

Un año después, el mismo periódico oficial del gobierno dio a conocer varias fábulas anónimas ${ }^{14}$, escritas "a la manera de anillo para el dedo de don Gerardo Barrios" y "dirigidas adonde quiera que se halle". El mandatario huyó del país luego de la derrota sufrida en el sitio de San Salvador a manos de las fuerzas militares guatemaltecas del general Rafael Carrera, que impusieron en el solio presidencial al licenciado Francisco Dueñas.

En 1865, tras ser capturado en Nicaragua, Barrios fue condenado al paredón de fusilamiento por un consejo de guerra, convocado por sus adversarios en la capital salvadoreña. Las fábulas mencionadas expre- 
san el rencor y animadversión populares presentes en las calles y círculos sociales de la época:

\section{El chompipe y la chorcha}

Un Pavo cojo y pesado

Que la cola desplegaba

Todo erguido y esponjado, A la Chorcha preguntaba

Con risible majestad:

- "Por tu vida, amiga, di, ¿Qué dicen en la ciudad
Cuando se trata de mí..?".

Contestóle ella de pronto:

—“¿Qué han de decir...? La verdad;

Se dice que eres un tonto

Henchido de vanidad".

\section{El polvo y el sol}

Un nubarrón de Polvo, que violento

Del suelo arrebataba

El borrascoso viento, $Y$ al cielo lo elevaba, Al claro Sol decía de este modo:
- "Mirame oscurecer tu ardiente fuego".

— "Si, le responde el Sol, pero muy luego

Vendrá la calma y volverás al lodo".

En 1875, el periódico El universo publicó, sin autor ni firma responsable, una fábula de tendencia esópica titulada El labrador y el burro.

Algún tiempo después, este aspecto de la literatura nacional fue retomado por el poeta salvadoreño-guatemalteco José Batres Montúfar (1809-1844) en $E l$ cazador $^{15}$, y por el dramaturgo, orador, poeta y funcionario público Francisco Esteban Galindo (1850-1896) en la parábola siguiente ${ }^{16}$, cuya temática se acerca al contenido de la fábula $E l$ bombre, el caballo y el toro, del venezolano Andrés Bello:

\section{El ingenio de azúcar}

iMurió la madre anciana!... A sus cinco bijos, que en sus mocedades amamantara en sus pechos y educara para el trabajo, dejó pingüe patrimonio. 
Numerosas suertes de caña, bornos y peroles para los caldos, casa de todo abastecida para la fabricación de azúcar, mascabado y panela, pilas para las mieles, y hermosa máquina de tres cilindros férreos, movida por enorme rueda, sobre la cual caía potente chorro de agua, desprendida de elevada acequia. He allí la berencia de la anciana.

Los cinco buérfanos, llenos de vida y de ilusión, pero faltos de experiencia, continuaron trabajando algunos dias y el ingenio siguió rindiendo abundantes productos.

Pero vinieron los abogados y en pos de ellos el Juez y el escribano. Hablaron los primeros del tuyo y del mio; y babló el segundo de la distribución de la berencia, y babló el tercero del papel sellado y de las costas.

$Y$ los jóvenes herederos los oyeron y quisieron dividir los haberes...

Pero dividirlos sin ventaja para ninguno, con igualdad absoluta... Hubo grandes, interminables disputas. Uno quería la tierra; otro quería la caña; el tercero alegaba exclusivo derecho a la casa; el cuarto a los utensilios; y el quinto a la máquina bidráulica.

Pero pensaron que la tierra y la caña y la casa y los utensilios de fabricación, nada valian sin la máquina; y que aquel a quien ésta tocara, impondría la ley a los otros.

Los abogados entonces transigieron: dividieron la finca en cinco lotes, y los herederos se llenaron de regocijo, viéndose ya cada cual propietario.

$Y$ en cuanto a la máquina, al mayor le tocó la rueda hidráulica, al segundo la atarjea y el agua, y los tres menores se distribuyeron los tres cilindros férreos.

Mientras la máquina, asi dividida por derecho, estuvo armada de becho, la finca siguió produciendo.

Pero un día se suscitó acalorada disputa entre los chicos: El dueño de la rueda pretendió que su pieza era la más importante, puesto que sin ella no se moverían los cilindros. El de la atarjea sostuvo llevar a todos la ventaja, puesto que el agua era el motor y sin ella el ingenio quedaría paralizado. El dueño del gran cilindro lo quitó para probar que sin su propiedad de nada serviría lo demás... Y el de la 
rueda la sacó del eje... Y los dueños de los cilindros inferiores, quitaron sus piezas... Y el de la acequia puso la compuerta... y cada uno se creyó vencedor de la disputa...

$Y$ la finca cesó de producir. La maleza fue invadiendo los cañales. El tiempo y el abandono bicieron su obra en la casa.

$Y$ entretanto cada beredero se empeñaba en probar que sin su parte de máquina, los otros se arruinaban; y que debian todos en consecuencia darle en la sociedad dividendos diferenciales...

$Y$ en el calor de la disputa, a veces, cada dueño se armaba de lo suyo contra los otros; y los cilindros rodaban por el suelo para machacar los pies de los enemigos; y la rueda también caminaba como máquina de guerra; y llovía el agua y caían pedazos de atarjea sobre todos y se bacía grande alboroto.

Habia unos vecinos cuerdos de cabellos rubios y ojos azules.

Fueron nombrados por el Juez tutores de los locos. Y un día se presentaron en la bacienda - restableciendo el orden a puñetazos $y$ patadas-. Y ellos armaron la máquina; reedificaron la casa; desyerbaron los cañales; repararon la atarjea y quitaron la compuerta; y siguió la finca produciendo y los locos vivieron presos en el hospital; y los tutores de los cabellos rubios y de los ojos azules bicieron suya la berencia y para ellos fue el azúcar, el mascabado, la panela y las mieles...

iAy de vosotros, ob pueblos centroamericanos, que si tenéis ingenio, es un ingenio de azúcar!

Entre 1877 y 1878, Luis Cromeyer, docente particular de francés y alemán, publicó varios epigramas y dos fábulas -El carretón y Otra, de tono ofensivo- en las páginas de El comercio, semanario agrícola, mercantil y de variedades editado en la capitalina calle de La Aurora, actual 8a. calle poniente:

\section{El carretón}

A cierto país del África

Remitió un comerciante,

Para aumentar el tráfico,
Un carretón flamante.

Grandísima la novedad 
Fue entre los arrieros Al ver llegar el carretón

Sin bueyes, tren ni aperos.

Vecinos, ¿̇a qué servirán

Las ruedas y este palo?

No tiene punta de arar

$Y$ tanta cama es malo.

iQué venga el cuerpo municipal

$Y$ en sesión permanente

Expliquemos qué utilidad
Este animal presente!

Se bizo asi. Se discutió.

Se pesó el pro y el contra

Sentada el acta dijo al fin:

inútil es el tarantín!

$Y$ despreciado el carretón

Quedóse sin empleo.

Quien no lo supo manejar

Es el inútil, creo.

Pese a ese desarrollo fabulatriz

salvadoreño, el doctor Esteban J. Castro afirmó acremente en 1881: “... yo no encuentro en El Salvador un fabulista como fray Matías [de] Córdova ni como García Goyena. La fábula del primero, que se titula $\mathrm{La}$ tentativa del león y el éxito de su empresa, por su originalidad, elevación del estilo y pensamientos, no tiene rival en la América Española, según el sentir de críticos competentes: ella eleva a su autor sobre Rafael de Azúa, único que en la América del Sur puede rivalizar con García Goyena, el Iriarte guatemalteco..."17.

$\mathrm{Al}$ año siguiente, un escritor nacional que firmaba sus escritos con el seudónimo de Efraim o Efraín publicó la siguiente traducción ${ }^{18}$, hecha de una composición francesa de autor desconocido:

\section{La niña y el sabio}

$A$ aquella de negros ojos, Sigamos hermosa niña Que al sonreir de la aurora

Por esta calle transita. ¿Qué busca tan de mañana? ¿Hacia dónde se encamina? Se para y llama a la puerta De su vecino alquimista. El noble anciano, sonriendo,

Sale pronto a recibirla, $Y$ en aquel laboratorio

Se ve entrar la jovencita. _ “iMe permite Ud., le dice, Una brasa de su bornilla,
Para encender nuestra leña En nuestra pobre cocina?". - "Muy bien, responde el anciano; Mas preciso es que te diga Que llevarla no podrás En tus manos tan pulidas. Aguarda, voy a buscarte Al instante un..." -y la niña, "Irá en mi mano", contesta Con dulcísima sonrisa. _ “En tu mano, si te quemas? iCuidado con ser loquita!". En menos tiempo que un cura

Moralejas en la oscuridad: la fábula en EI Salvador del siglo XIX 
Exclamara "Ave María”,

En el bueco de la mano

Pone un poco de ceniza,

$Y$ colocando sobre ella

Las materias encendidas,

Con sonrisa cariñosa

Da un saludo al alquimista,

$Q$ ue dice meditabundo

Viendo partir a la niña:

- “iCuán vana cosa es la ciencia!

En la infancia está la mía,
A pesar de tanto estudio

En treinta años de vigilias.

Yo, doctor de la Sorbona,

Hecho tal cosa no habría;

Por eso Zenón ba dicho

Con demasiada justicia:

-El que es muy sabio no es tanto

Que en el curso de su vida, No llegue a ignorar a veces Aun las cosas más sencillas.”

En contraposición a los autores ya mencionados, en 1886 el poeta colombiano Rafael Pombo editó, como parte de su libro Fábulas y verdades, su composición El paraguas soberano, en la que atacaba el fracaso de la federación centroamericana acaecido unas décadas atrás, concepto que fue comentado y repudiado acremente en 1890 por redactores anónimos de los periódicos La república de Centro América y La unión.

Como continuación de la línea de reflexión y teorización sobre la fabulística nacional y universal, el historiador, polemista y catedrático de retórica Francisco Castañeda (1856-1925) expresó en su libro Lecciones de retórica o literatura preceptiva (1885): "El apólogo o fábula es una composición de carácter mixto en que, bajo el velo de la alegoría, se encierra una verdad deducida de hechos en cuyo desarrollo por lo general sólo figuran seres irracionales. El carácter mixto del apólogo depende de que puede conceptuarse, ya como un pequeño drama, ya como una diminuta epopeya, con su acción, personajes, enredo y desenlace; siendo aplicables, en consecuencia, a esta corta composición, en la medida que sus dimensiones lo permiten, las reglas que sobre tales puntos se han dado al hablar de aquéllas."

Y agregaba: "Respecto a los personajes de la fábula, adviértase, además, que deben presentarse con los atributos naturales que les pertenecen, para no faltar a la verosimilitud poética ni a la realidad de las cosas: así, por ejemplo, el león aparecerá fuerte y animoso; el perro, fiel; noble el caballo; el zorro, astuto, etc., etc. En el caso de que los actores sean seres racionales u objetos inanimados o abstractos, se observará 
siempre la misma regla de presentarlos según sus propiedades reales, o las que la preocupación o el raciocinio les atribuyan."

Castañeda concluyó su planteamiento didáctico anotando: "La verdad, reflexión o doctrina de una fábula se llama moraleja: puede colocarse indistintamente al principio (afabulación) o al fin (posfabulación), aunque esto último es lo más usado. De todos modos, lo que se exige es que la verdad o reflexión brote del relato con tal espontaneidad, que no sea substituirla con otra. Este es la condición esencial de todo buen apólogo.”

Vinculado más con las labores propias del creador artístico que con las del teorizador, Calixto Velado (1855-1927) escribió en 1889 la traducción castellana de ciertos pasajes de Les Chatiments (1853) - del poeta y novelista francés Víctor Hugo ${ }^{19}$ - y algunas fábulas de su propia pluma ${ }^{20}$.

Por su parte, el poeta y dramaturgo Joaquín Aragón dio a conocer, en 1893, su trabajo fabulesco La rosa y el jardinero ${ }^{21}$ :

Muy airosa se mecia en el rosal una rosa; $y$ al mirarse tan hermosa

en altas voces decía:

"Donosura y gallardia me ha concedido Natura; ¿quién me iguala en hermosura?, ¿quién en aroma me gana? A ser del jardín sultana me ha traido la ventura.

Y el jardinero, de fijo, viéndome imperar aqui ba de prendarse de mi, que a las flores mando y rijo."

Así la orgullosa dijo

y llegando el jardinero que, oyó su discurso entero, jovial y a la vez adusto replicó: no te doy gusto, a la violeta prefiero.
Pues de su aroma a pesar tan sutil, como exquisito, modesta en un rinconcito vive y crece sin charlar; tú vives para engañar, ella no lo sabe bacer; a ti se te balla doquier, pues te afanas por lucir, $y$ ella si se bace sentir apenas se deja ver.

Asi dijo el jardinero $y$ una violeta cortó; $y$ la rosa se meció con un vaivén altanero; mas del sol al rayo fiero se la vio palidecer.. Rosa, violeta o mujer, mira en ambas tu figura: nada vale la bermosura sin la virtud y el saber. 
Otras personas que le dieron continuidad a la fabulística salvadoreña fueron el poeta y crítico literario Antonio Guevara Valdés (18451882) — con su composición satírica De lejos, de cerca, por fuera y por dentro ${ }^{22}$ - Salvador G. Hernández —autor de La rosa y el sauce ${ }^{23}$, era un pedagogo nacido en San Miguel en 1859 y fallecido el 15 de noviembre de 1893-, Rosa Carreto — de incierta salvadoreñidad, con su trabajo La abeja y la mariposa ${ }^{24}$ - y el vate Miguel Plácido Peña.

Venido al mundo en Chalatenango el 5 de octubre de 1862 y muerto en San Salvador el 26 de octubre de $1896^{25}$, el escritor, periodista, diputado (1893) y abogado infieri Miguel Plácido Peña contribuyó a la labor fabulesca nacional con su texto La doncella, el mono y el león ${ }^{26}$. En su breve existencia, Peña —escritor contemporáneo del movimiento modernista centroamericano- fue autor del poemario Inspiraciones (1884), de la letra de un Himno a Bolivar (1892, con música del maestro Rafael Olmedo) y de muchas composiciones poéticas publicadas en El eco nacional (San Salvador, 1891-1894), Centro América (Santa Ana, 1890-1894) —ambos periódicos defensores del régimen golpista de los generales Carlos y Antonio Ezeta- y El diario del hogar (México, 1892).

\section{La doncella, el mono y el león}

Encontróse al acaso una doncella en un bosque perdida, $y$ al verla un mono tan hermosa $y$ bella

la llevó a su guarida $y$ satisfizo en ella sus deseos

tan torpes como feos. A los gritos que daba la criatura un león acudió, y con tal bravura se lanzó sobre el mono que, al instante,

el mono quedó en tierra agonizante.

Llevó a la niña a

su caverna oscura

el león generoso, $y$ — “toma aliento"- afable le decia; - "no te asombre mi fiereza, ni pienses que yo intento darte la muerte... amigo soy del hombre... soy tu libertador, vive dichosa, vive en paz y tranquila, niña bermosa".

Cuando ya más confianza en él tenía que hasta le acariciaba en la melena, a la niña el león le dijo un día: "ya te ha pasado el susto, ya estás buena para servirme puesto que eres mía", 
$\mathrm{y}$ asi, entre broma y broma

$y$ entre abrazos,

fue engulléndose de ella los pedazos.

iCuántas veces se vende un enemigo, como gato por liebre, por amigo!
iY cuántos, cuántos en el bien que ban becho

no buscan más que el personal provecho!

iNunca os confiéis de los que son, señores, asi como el león, libertadores!

En los años finales del siglo XIX, las páginas de El municipio salvadoreño dieron cabida a una composición fabulesca - referente al ejercicio del poder por la fuerza bruta ${ }^{27}$ - del fallecido doctor y literato Samuel Martínez, extraída de un cuaderno manuscrito conservado con celo por su hijo, Francisco Martínez Suárez.

Por la misma época, Francisco Gavidia (1863-1955) - patriarca y fundador de las letras nacionales- se introdujo de manera efímera en el terreno fabulatriz universal, debido a sus exploraciones artísticas y literarias de corte modernista y cosmopolita, compartidas con su amigo y discípulo nicaragüense Rubén Darío (1867-1916).

Gracias a sus inquietudes intelectuales, Gavidia realizó gestiones para que ingresara al país un ejemplar de las Pbaedri Fabule (Fábulas de Fedro), como parte de un cargamento de tomos que la Librería Francesa de Ítalo Durante y Cía. importó, en diciembre de 1904, para la naciente Sección de Humanidades Clásicas de la Biblioteca Nacional. En las estanterías de dicho centro cultural, fundado por decreto gubernamental en 1870 y abierto al público hasta en 1888, las personas lectoras también podían encontrar un volumen de Fábulas de Esopo (Madrid, José Astort y Cía. editores, 1871), traducidas por Eduardo de Mier del griego y de las versiones latinas de Fedro, Aviano, Aulo Gellio y otros autores.

Además, Gavidia tradujo y adaptó a las formas castellanas de prosa y verso — que semejan a las de Pombo- algunas fábulas clásicas ${ }^{28}$, aparte de que comentó los orígenes y temas de otras composiciones fabulísticas ${ }^{29}$, pero sin llegar a escribir las suyas propias, como lo evidencia su traducción "al modo castellano" de la clásica fábula 


\section{Las hormigas y la cigarra}

Sus viveres mojados

En horas del Invierno,

Secaban las Hormigas;

Pidióles alimento, Hambrienta la Cigarra.

Las Hormigas dijeron:

- ¿Pues cómo en el Verano

No entrojaste sustento?

La Cigarra responde:

-No tal; todo ese tiempo
Cantaba musical-

Mente. Y ellas riendo, -Pues quien canta en el Verano, Que baile en el Invierno.
Esta Fábula enseña, No ver con menosprecio
Las cosas de la vida
$O$ pasar por extremos.

Otros cultores de la fábula nacional fueron los poetas y pedagogos Carlos Arturo Imendia (1864-1904) —autor de La piedra falsa y el brillante, La flor y la fuente y El león y el castor ${ }^{30}$ - y Salvador Díaz Roa, vástago de Miguel Díaz y Natalia Roa, nacido en Izalco (Sonsonate) en 1870 y fallecido en la misma localidad en 1909.

Graduado como docente de la Escuela Normal de Maestros (1878) — dirigida en ese entonces por Gustav Radlach (Berlín, Alemania, 1848Chinameca, San Miguel, a comienzos del siglo XX) y después por el colombiano Francisco Antonio Gamboa (Cali, 1861-San Salvador, 1908) - , Díaz Roa fue director del tecleño Liceo San Luis tras el fallecimiento de su fundador, Daniel Hernández (1849-1896). Casado en Santa Tecla con Tula Medina, con quien procreó cinco hijos, se desempeñó como inspector zonal de instrucción primaria y redactor de la revista La nueva enseñanza. Por encargo gubernamental escribió la obra Apuntaciones pedagógicas (San Salvador, Tipografía Salvadoreña, 1904, 152 págs.). Las revistas La república de Centro América (1897), La quincena (1903-1907) y Repertorio del Diario del Salvador acogieron las producciones literarias y fabulescas de Díaz Roa, entre ellas Los perros, El cerdo y el pollino y El gato y la culebra ${ }^{31}$.

A Imendia y Díaz Roa corresponden las respectivas autorías de los trabajos venideros: 


\title{
La piedra falsa y el brillante
}

\author{
A Francisco Gavidia
}

"Si en tus pretensiones locas

Supones que tu valor

Es al mio superior,

Por desgracia te equivocas.

Tú en un anillo, yo en cruz,

Lucimos siempre arrogantes,

$E$ iguales son los cambiantes

Que forma en los dos la luz.

Tú adornas, $y$ con derecho,

La mano de una señora,

Quien no cree que se desdora

Cuando nos lleva en su pecho.

¿Qué tengo, pues, que envidiarte?

$N i$ en origen me superas,

Pues ambos, aunque no quieras,

Somos de uno mismo: el arte."

De tal suerte se expresó

El simil altivo y necio;

El brillante, con desprecio,

Cuentan que así contestó.

"Ese empeño en demostrar

Que en todo somos iguales,

Lo que prueba es que no vales

Cuanto tú quieres probar.

Del mérito verdadero

Es la modestia la valla:

Quien algo vale, lo calla,

Quien se elogia, es embustero.

Voy, pues, en esta ocasión,

Contra mi modo de ser,
A enseñarte a comprender

$T u$ gran equivocación.

Si mostrar quieres con mañas

Que yo no soy superior

A tu mediano valor,

A fe mia que te engañas.

Tú en una cruz, yo en anillo,

Hoy colocados nos vemos;

Mas sabe que no tenemos

En nuestro cuerpo igual brillo.

La luz que irradia en los dos, De distinto origen parte: A ti te lo ba dado el arte, A mi me lo ba dado Dios.

Nací con ella encerrada $Y$ la puedo llamar mía, Pues vive en mi noche y dia... Tu débil luz es prestada...

Decir que en nuestro arrebol No bay diferencia ninguna,

Es afirmar que la luna Brilla tanto como el sol.

Has hablado sin decoro, Viendo que en todo eres pobre; Tú estás engarzado en cobre, Yo estoy engarzado en oro.

El tiempo tu falsedad Probará con desengaños... Que pasen algunos años $Y$ no babrá en ti vanidad. 
Que en esta varia existencia Al cabo llega el momento

En que se ve el fingimiento $Y$ en que buye toda apariencia."

$Y$ asífue: pasó el engaño, Desvanecióse el matiz;

La piedra perdió el barniz, El cobre perdió su baño.
Yya sin ficticio velo, Extraída de su caja, Rodó la envilecida albaja, Despreciada, por el suelo.

Mientras el bello diamante Brilló en toda plenitud, Como brilla la virtud, Siempre modesta y triunfante.

\section{El cerdo y el pollino}

La desgracia juntó por un camino a un cerdo y a un pollino.

El hambre los tenía en tal aprieto, que apenas si traian esqueleto.

"Por lo que veo —el cerdo dijo en broma-

ya tengo qué comer o quién me coma".

Movió el asno de gozo las orejas, $y$, la voz esforzando, le dijo: "Ni te dejo ni me dejas; vamos, vamos andando".

"En desgracia tan grande, companero -

clamó el cerdo- no veo otra esperanza

que arrostrar con tesón todo destino, ora sea en chiquero, ora en corral, en calles o labranza, como quien juega el todo por el todo, mas con cordura y tino, $y$ ello ba de ser de modo que por mitad tomemos todo lo que ganar nos proponemos".

"Con tal que a mis colegas no refieras... -el asno replicólo que tú quieras: porque al honroso título que abona

mi distinguido oficio, no siempre sienta bien cualquier servicio, según mi sociedad me lo pregona”.

"Esas tenemos, ¿no?

—dijo el cerdoso-,

pues a fe, gran borrico, que mereces,

por tonto y vanidoso, todas las privaciones y reveses

que experimentas boy.

¿Que te avergüenza

recurrir a trabajos de otra clase? ¿Sólo para un oficio Dios nos hace? 
iMuy diferente este tu cerdo piensa!

iNi babia de ser cerdo

si por obrar de acuerdo

con la tal sociedad,

que ni me nombra,

me entregara a la muerte

becho un andrajo,

cuando sé que ora en luz, ora en la sombra,

la dicha be de encontrar

con mi trabajo!

¿Y esa del cerdo luminosa bola, al pollino, no más, fue dirigida?

Puede; pero enseguida

muchos hombres tocó

por carambola.

Como parte de la difusión de las lecturas fabulescas en el público nacional, desde las dos últimas décadas de la centuria pasada hasta inicios del siglo XX el Repertorio salvadoreño -órgano mensual de la Academia de Ciencias y Bellas Letras de San Salvador-, Revista de la enseñanza, La nueva enseñanza (1896), La escuela salvadoreña, y las ediciones mensuales y quincenales del Repertorio del Diario del Salvador incluían fábulas en verso y prosa de autores clásicos y modernos.

Así desfilaron ante los ojos del público salvadoreño breves textos fabulescos de Esopo, Samaniego, Timoneda, García Goyena, Pombo, Leopoldo Cano, La Rochefoucauld, Víctor Hugo, Joaquín V. González, Sales Pérez, Tolstoi, Pérez Galdós, Blanco Belmonte, Wilde, Zúñiga, José Selgas y Carrasco, Picon, Iriarte, Campoamor, Hartzenbusch y varios autores anónimos, árabes algunos de ellos.

Por otra parte, esa difusión de textos fabulatrices tuvo como elementos coadyuvantes a los libros de texto usados en las escuelas públicas y colegios del país. Entre dichos materiales, sobresalían los volúmenes de la serie de lectura Mantilla, creados por Luis F. Mantilla - catedrático de Lengua y Literatura Española en la Universidad de New York-, impresos en Bélgica y distribuidos a nivel latinoamericano por la casa editorial parisiense de la viuda de Charles Bouret.

Quizá haya sido en estos españolizados libros de lectura en los que se nutrieron las jóvenes mentes de los que más tarde serían los fabulistas de la primera mitad del siglo XX, plumas entre las que se destacarían las del sonsonateco Salvador Salazar Arrué (Salarrué) y del cojutepecano León Sigüenza.

Pero este último punto es ya tema para una futura confabulación investigativa, emprendida entre los dispersos como incompletos valles de la historia literaria salvadoreña. 


\section{Notas}

1. El tema de la fabulística salvadoreña fue esbozado por María B. de Membreño en los capítulos I y II, libro XV, de su segundo tomo de Literatura de El Salvador (San Salvador, inédito, 1959) y por Miguel Ángel Chinchilla en su artículo $A$ manera de brevísima introducción a la fábula en El Salvador (Casa de los cantos, No. 3, enero-marzo de 1983, revista de las Casas de la Cultura de Olocuilta, San Pedro Nonualco, Santiago Nonualco y Zacatecoluca, departamento de La Paz, El Salvador, págs. 5-8).

Dicho asunto también fue tratado por Luis Melgar Brizuela en su libro de texto para séptimo grado, Idioma Nacional (San Salvador, Oxcelotlán, 1995, págs. 193198). Además, Miguel Ángel Chinchilla y Carlos Cañas Dinarte lo abordaron en la conferencia Desarrollo de la fábula en El Salvador. Homenaje a León Sigüenza, charla organizada por el Departamento de Letras de la Universidad de El Salvador y la Fundación "María Escalón de Núñez" (desarrollada en el auditorium 3, Ciudad Universitaria, San Salvador, a las 4 p. m. del viernes 10 de noviembre de 1995).

A esos trabajos se suman Albertina Herrera y Cañas Dinarte con el artículo Desarrollo bistórico de la fábula en El Salvador (Suplemento cultural Tres mil, 293, San Salvador, Diario latino, sábado 16 de diciembre de 1995, págs. 14-15), al igual que el periodista Héctor Silva Ávalos con sus breves reflexiones en el apartado Sobre la literatura infantil salvadoreña (Revista Eco, La prensa gráfica, San Salvador, miércoles 24 de abril de 1996, pág. 4-B).

Cañas-Dinarte ha desarrollado con más amplitud el tema en Confabulaciones. Apuntes para una bistoriografía de la fabulística salvadoreña (en el volumen colectivo Juegos florales 1996, San Salvador, Dirección de Publicaciones e ImpresosCONCULTURA, 1997, págs. 247-302) y en Moralejas en la oscuridad: la fábula en El Salvador del siglo XIX (San Salvador, revista Cultura No. 83, 1998).

2. ¿No. 62 o 64?, octubre de 1825. La referencia y el texto de la fábula aparecen citados por Ítalo López Vallecillos, El periodismo en El Salvador (San Salvador, UCA Editores, 1987, 2a. edición, págs. 65-67).

3. Editado en la Imprenta del Gobierno, San Salvador, trimestre I, No. 12, domingo 13 de julio de 1828 , pág. 48.

4. San Salvador, No. 14, jueves 17 de agosto de 1843, págs. 107-108, sólo calzada por las iniciales F. D.

Bajo el título de Fábula referente a la unión de Centro América. Versos de Francisco Diaz, Vicente Acosta reprodujo este mismo trabajo poético en La quincena, San Salvador, año II, tomo III, No. 27, 1 de mayo de 1904.

5. San Salvador, tomo I, números 16 al 19, ediciones del 9 al 30 de julio de 1847.

6. Cfr. aviso al pie de la 3a. columna, Gaceta del Salvador en la república de Centro América, San Salvador, tomo 2, No. 87, 1 de noviembre de 1850, pág. 4.

7. Ibid., tomo 3, No. 48, 21 de mayo de 1852.

8. La juventud, San Salvador, año V, tomo III, 1 de junio de 1882, págs. 325-327.

9. Ibidem.

10. El rol, San Vicente, Imprenta del Día, año 2, No. 49, 16 de febrero de 1856, pág. 4 .

11. Gaceta del gobierno del Salvador en la América Central, Cojutepeque (Imprenta del Triunfo), tomo V, No. 39, jueves 13 de marzo de 1856, pág. 4.

12. Ibídem, tomo VI, No. 48 , sábado 10 de octubre de 1857 , pág. 8 .

13. Gaceta oficial de la república del Salvador, San Salvador, tomo 11, No. 14, jueves 
8 de enero de 1863 , pág. 6 .

14. El constitucional, San Salvador, tomo 1, Nos. 15 y 16, jueves 21 y 28 de enero de 1864, pág. 3.

15. Poesías, San Salvador, Departamento Editorial del Ministerio de Educación (Biblioteca Popular, 28), 1961 y Guatemala, Editorial "José de Pineda Ibarra", 1962, págs. 15-18.

16. Publicada en periódicos y revistas como Repertorio del Diario del Salvador (volumen VI, No. 31, 1 de enero de 1906, págs. 1360-1361) y Suplemento literario dominical del Diario del Salvador (tomo II, No. 25, 26 de febrero de 1911, págs. 413-414).

17. Discurso al hacerse cargo de la presidencia de la Sociedad Literaria "La Juventud", revista La palabra (San Salvador, año I, Nos. 2 y 3, 15 de junio y 1 de julio de 1881, págs. 11-14 y 19-22).

18. Fechada el 28 de julio de 1882, fue impresa por La juventud, año VI, tomo IV, 8 de octubre de 1882, pág. 221.

19. Bajo el título de Fábula o bistoria, esta adaptación castellana fue divulgada en la revista La república de Centro América (San Salvador, volumen 1, No. 4, diciembre de 1897, pág. 204) y en las páginas 55 y 56 del libro de poemas de Velado intitulado Arte y vida (San Salvador, Tipografía La Unión, 1922).

20. Un bien con un mal se paga, publicado en Arte y vida, pág. 138. El Repertorio del Diario del Salvador - volumen IX, No. 53, 1 de enero de 1907- dio a conocer una fábula con el mismo título, solo que firmada por Joaquín Zaldívar.

21. Dirigida por su propietario Próspero Calderón en la capital chapina, la "revista de ciencias, artes y literatura centroamericanas" Guatemala ilustrada acogió dicha fábula en las páginas 558-559 de la edición No. 44, año I, domingo 16 de julio de 1893.

22. Publicada en La juventud, tomo III, 1 y 15 de abril de 1882 (edición dedicada a la memoria de dicho autor y crítico literario), fue rescatada por Mayorga Rivas, Guirnalda salvadoreña, tomo II, Imprenta Nacional del Dr. Sagrini y Dirección de Publicaciones, 1885 y 1977, págs. 71-72.

23. El cometa, San Salvador, año IV, No. 78, lunes 14 de marzo de 1881, págs. 647-649.

24. La fortuna, San Salvador, año I, No. 11, 15 de noviembre de 1882, pág. 8.

25. Fechas de nacimiento y muerte que, con base documental, refutan a las de 1853, 1861 y 1913, manejadas por Luis Gallegos Valdés (1981), David Escobar Galindo (1982) y Carlos Cañas Dinarte (1996).

26. Mayorga Rivas, op. cit., tomo III, 1886 y 1977, pág. 203, reproducido en Camurati, Mireya. La fábula en Hispanoamérica, México, UNAM, 1978, pág. 232.

27. Publicada en la edición del año I, No. 40, jueves 12 de diciembre de 1889, pág. 4. Los dos ejemplares de ese periódico archivados en la sección de Colecciones Especiales de la UCA se encuentran dañados por la acción de la humedad y los insectos, por lo que el texto de la referida fábula está severamente mutilado.

28. Las traducciones gavidianas en verso y prosa de las fábulas de Esopo y Babrius fueron impresas en La quincena (año II, tomo IV, No. 43, 1 de enero de 1905), en el tomo I de sus Obras (Poemas y teatro), San Salvador, Imprenta Nacional, 1913, pág. 494 y en el tomo II de Obras completas, San Salvador, Dirección de Publicaciones, 1976, págs. 130-131.

Estas versiones merecieron una brevísima mención de su nieto, José Mata Gavidia, en su biográfica Magnificencia espiritual de Francisco Gavidia (San Salvador, Di- 
rección de Publicaciones, 1969, 2o. Premio República de El Salvador, Certamen Nacional de Cultura, 1965, pág. 206) y otra en el escrito preliminar de CañasDinarte Confabulaciones..., pág. 276.

Al polígrafo salvadoreño se debe también una traducción de una fábula adaptada al inglés por John Gay (1685-1732, fáb. 47, libro I, La corte de la Muerte); al francés por Jean-Pierre Claris de Florian (1755-1794, como una de las 89 composiciones contenidas en su tomo de Fábulas, 1793); al italiano por Lorenzo Pignotti (1739-1812, La morte e il medico, en su obra Favole e novelle, Pisa, 1782) y al castellano por Félix María Samaniego (1745-1801, La Muerte, fáb. XI, libro VI, 1784). Basado en Florian, Gavidia tradujo y publicó dicha composición en La república de Centro América (volumen 2, No. 8, agosto de 1898, pág. 399) bajo el título de La muerte escoge su Primer Ministro.

29. Véase El asunto del poema en Fray Matías [de] Córdova, publicado en las Notas científicas y literarias de Repertorio salvadoreño, San Salvador, tomo I, No. 2, 15 de septiembre de 1888 .

30. Insertas en las págs. 197-200, 205-208 y 321-323 de su libro Lugareñas (San Salvador, Imprenta Nacional, 1894, 448 páginas), prologado por Francisco Gavidia.

La piedra falsa y el brillante - con el título de El símil y el brillante - fue publicada por Repertorio salvadoreño, tomo III, No. 6, diciembre de 1889, págs. 427-429.

31. Escritas en Izalco, departamento de Sonsonate, esas fábulas de Díaz Roa fueron publicadas por el Diario del Salvador (27 de julio de 1907 y 13 de julio de 1908) y por el Repertorio del Diario del Salvador, 67, octubre de 1908. 